\title{
Development of Public-Private Partnership in the Field of Educational Services
}

\author{
Gulshat Duzelbayeva (PhD) \\ Almakul Abdimomynova (PhD) \\ Akmaral Baimahanova (MA) \\ Akmaral Mukhtarova (MA) \\ Akzhan Karbozova (MA) \\ Kyzylorda State University, Kazakhstan
}

Doi:10.19044/esj.2018.v14n28p59 URL:http://dx.doi.org/10.19044/esj.2018.v14n28p59

\begin{abstract}
Public-private partnership in the field of education is a special form of cooperation between the state and business. It is built on the unification of resources that are available at their disposal. These resources are primarily intellectual resources and it entails the use of mutual advantages. Its goal is to provide socially significant services with mutual additional benefits on the basis of pre-calculated risks. This is due to the understanding that the effective implementation of the State's socio-economic programs depends, inter alia, on the level of development of business structures, which practically implements the priorities formed by the state. Nevertheless, Kazakhstan's small business is not always able to develop independently in the context of demand by the modern conditions of the national economy.
\end{abstract}

Keywords: Public-private partnership, intellectual capital, small business, education

\section{Introduction}

The state in the modern economy is responsible for various social structures of society in providing socially significant public goods, which explains the tendency to preserve economic entities in state ownership. Within the framework of state ownership, some rights are delegated to the private sector, which brings private goods and services and creates conditions for effective functioning and management and the rational management of resources (Deryabina, 2008).

In this regard, there is a problem associated with the need to effectively attract the state to participate in the development of the market economy mechanism i.e. Public - Private Partnership (PPP). 
One of the most complete PPP classifications has been developed by the World Bank, which defines "the methods through which a private company can be involved in a project" (Pierson, 1959): management contracts and leases; concession; projects involving new construction; and partial privatization of assets.

The form of PPP in the field of education is determined by the allocation of the object of management: institutional - the object of management is an organization or a structural unit; program-project - the initiative of partners is aimed at the project or program.

\section{I.}

Public-private partnership is supposed to be considered as an alternative to direct and indirect methods of the development of the educational system. Direct methods include direct state orders, which are tenders provided by the relevant system of Market Contracting. The methods of indirect financing, supporting the Institute of PPP, include tax benefits received by private businesses engaged in educational activities. The degree of development and national characteristics of market relations depend on the methods, forms, and nature of relations within the framework of the partnership. This involves the preservation of the state performing socially responsible functions related to national interests, and the business which performs the function of stimulating the development and the increment of new knowledge. Public-private partnership allows the distribution of business risk between private and public sectors of the national education system. This sector contributes to the implementation of national economic strategy and improves the competitiveness of the country, which in turn leads to an increase in long-term socio-economic effects.

The most important prerequisite for the emergence of PPP in education is the alliance nature of the relationship of PPP participants. As a result, it requires fundamentally different approaches that can predict the effectiveness of their activities and the quality characteristics of educational services. In the formation of public-private partnership in the field of education, there are both economic benefits of integration of PPP participants (reduction of interest rates in the provision of loans, profit distribution, reduction of tax payments, obtaining intellectual property rights, acquisition of property as a result of redistribution between the partnership participants, etc.) and non-economic benefits (obtaining explicit and implicit knowledge, formation of professional competence of employees, flexibility of organizational technologies and programs that provide cultural mobility of employees, formation of public opinion about the company, etc.).

Thus, some important characteristic of public-private partnership as an educational alliance are shown below: 
1. Collective organization of the educational process, which implies the expansion of the number of subjects of educational services (government, business, employers, educational services providers - educational institutions).

2. Collective diversity of the object of assignment of knowledge, skills, explicit, implicit competence of employees, flexibility of educational technologies, programs, cultural mobility of employees.

3. Reduction of social risks in assigning the consequences of the results of PPP activities in connection with the formation of adaptive opportunities for differentiation of educational services and their results for further implementation.

4. Innovation activities in the framework of a PPP in connection with the necessity of taking into account the aspirations of the business based on continuous innovation, competitive production technologies, and management processes.

5. Assignment of monopoly rent as an experience of coordination of formal and informal interaction of participants of public - private alliance relations.

6. The multifunctionality of the forms of assignment: the assignment of non-economic benefits (exchange of knowledge, routines, customs, etc.) and economic assignment (profits, benefits). Thus, the process of creating educational alliances within the PPP is not limited to the sphere of production of educational services, but is formed at the stages of coordination in the organization of the alliance; distribution, exchange, and consumption of the results of education services.

In our opinion, the sphere of education is being reformed in connection with the process of transition of the modern community to the knowledge economy, which changes the degree and scale of involvement of the public and private sectors in the educational system as a socially significant public good, which leads to the evolution of the forms and methods of the organization of educational services. The formation of a balanced and integrated national educational system depends on the effective combination of mixed organizational and economic forms, within which the creation, accumulation, dissemination, and mass introduction of new knowledge and technologies was carried out.

The education sector cannot be fully transferred to the private sector because of its social importance. However, the lack of effective forms of management and financing from the state structures does not always allow for a qualitative increase in the quality of training, which is adequate to the requirements of the modern labor market.

At the same time, the educational process should facilitate the implementation of state functions related to the security of the individual, society, and the national economy and their protection from internal and 
external threats. Education, as an instrument, and at the same time the context of socialization of citizens, should equip them with knowledge about the content and nature of the state policy and the conditions of ensuring the internal and external security of society (Savransky, 2007).

At the same time, the implementation of public-private partnership in the field of vocational education is possible under the following conditions:

1) maintaining the social significance of vocational education: ensuring timely, adequate, quality and affordable education;

2) integrity of PPP projects;

3 ) the definition of mutual interests and risk management of PPP;

4) control over the use of income and expenses received in the implementation of PPP;

5) provision of full information on the process of implementing partner activities;

6) definition of the conditions and procedure for the dissolution of the partnership.

The quality of partnership in the field of education is determined by the balance of economic interests of the participants interested in improving the quality of life of the population in the application of market mechanisms in the provision of socially significant public goods. In particular, for educational institutions, the transformation is manifested as a result of changes in the structure and content of the financing process. It is also manifested as a result of the provision of additional services to obtain sustainable competitive advantages in the market. For the private sector, the transformation is manifested as a result of participation in the process of providing private benefits of social importance and the possibility of attracting knowledge as an intangible asset in installments. This can be seen in the case when the return of investment is carried out at the expense of tax revenues, taking into account the previously agreed interest rate.

Public-private partnership in Kazakhstan has become a more profitable investment for potential investors. This type of cooperation between the state and business is currently the most attractive for private capital, as it has a number of guarantees from the state. The main goal of public-private partnership is the development of infrastructure in the interests of society. However, this can be achieved by combining the resources and experience of the state and business, the implementation of socially significant projects with the lowest cost and risk, and the provision of the economic entities of high quality services.

The relationship between the public partner and the private partner is governed by the laws on "public-private partnership" of 31 October 2015, on "concessions" of 7 July 2006, and the relevant by-laws (Law of the Republic of Kazakhstan, 2015). 
At the end of 2017, 245 PPP contracts were signed in Kazakhstan. About 100 more projects are at the stage of signing. Most of the contracts are in the education sector - 52\%; health - 19\%; culture and sports - 14\%; and the rest $15 \%$. Leaders based on the number of projects implemented include: Aktobe (73 projects), East Kazakhstan (71), and Karaganda (21) regions. The total amount of signed and implemented contracts throughout the country reached 96,6 billion tenge (Statistical Yearbook, 2017).

In order to use a favorable scenario of partnership development in the field of training, it is necessary to develop franchise education systems (branches, subsidiaries), which allows positioning the system of training qualified personnel for entrepreneurship depending on the territorial coverage, implemented educational programs, and the national and regional requirements for entrepreneurship. Thus, this makes it possible to identify strategic groups of participants in the educational process in the face of traditional universities, commercial business schools, and training centers of the national and local employment services.

In the study, we have identified barriers that prevent educational institutions from moving from one strategic group to another: for universities - insufficient experience in practical training; for business schools - insufficient experience in conducting research due to the high cost of the latter and the uncertainty of the prospects of payback; for the regional system of training and retraining - insufficient funding and the relative unattractiveness of the regional market of educational services for large commercial business schools and classical universities.

Special programmes for small and medium-sized businesses should take into account the increasing social and economic role of small and mediumsized enterprises. Thus, these programs can be developed both by business schools (university or private) and various government agencies.

1. Programs that meet the demand of the representatives of business structures of small and medium businesses at various stages of development: the organization of business; development of the existing business; the globalization of business and entry into foreign markets; diversification and differentiation of small and medium companies.

Furthermore, training programs should be developed depending on the scope of small and medium business. They should include:

- programs that show the changes in the external environment, develop skills to analyze factors that do not affect business development;

- programs that develop the management of various aspects of activity (quality management, crisis management, etc.);

- programs aimed at qualification competencies, taking into account the specifics of the multifunctional activity of the entrepreneur manager of a small and medium-sized company; 
- programs of integral or interdisciplinary nature (strategy, change management, etc.).

2. Programs that develop the institutional environment, which is focused on the support and development of small and medium-sized enterprises in the form of training of government officials at various levels: independent organizations (for example, development agencies) and financial institutions such as business incubators, business centers, science parks, business education, and consulting firms.

3. Programs of higher education institutions focused on the demand of entrepreneurs for personnel of certain competencies (special courses in bachelor's and master's programs, elective courses in MBA programs, University business schools).

4. Programs for schools and colleges based on the system of secondary and secondary special education, which is focused on the development of entrepreneurial characteristics of the individual and the ability to identify, analyze, and solve problems.

5. Programs for small and medium-sized businesses based on the conditions of rapidly changing demand for production human resources, implemented through Training centers of the national and local employment services (Kolesnikova, 2010).

Subsequently, educational programs for entrepreneurs of small and medium-sized businesses should be supported by the state, including the principles of co-financing. The lack of financial support for the organization and conduct of training and retraining is one of the reasons for the active development of entrepreneurship.

It is necessary to develop a national model for the application of PPP in education. The objectives of which should be formed and implemented in connection with a national strategy that takes into account resource and financial conditions for increasing the efficiency and competitiveness of the education sector, growth of investment attractiveness of the financial capacity of educational institutions, improvement of economic mechanisms, while ensuring high quality of educational services and the observance of the constitutional rights of citizens in the field of education.

The implementation of strategic goals is associated with the consistent solution of a number of tasks. Therefore, it takes into account the strategic objectives of the state policy in the field of education and organizational and legal opportunities for the creation of PPP in the Republic of Kazakhstan. Their goal includes:

- maintaining the social significance of educational services;

- creation of a mechanism of voluntary economic support for education;

- involvement of the private sector in the management of the content component of education on a certain range of issues; 
- definition of the principles of effective property management of educational institutions;

- creation of a partnership basis for research, development and technological works, as well as joint research activities.

The special status of PPP participants, as well as the priority of socially significant goals of its functioning, including the social nature of the benefits and advantages, determines the special system of economic relations between them.

The subjects of the partnership from the public sector may be: public authorities, including education management bodies and local selfgovernment; non-profit organizations operating in the field of education; state, municipal educational institutions of secondary and higher professional education; and state commercial organizations (state and unitary enterprises implementing programs in the field of education).

From the private sector, entities may be commercial and non-profit organizations of various organizational and legal forms of ownership with or without the participation of the state, including non-governmental educational institutions i.e., individuals. The spread of the various forms of public-private partnership in the field of education is necessary with the use of public interaction and control in the form of expert councils and public committees that coordinate the actions of partners (Bondarenko, 2008).

Measures to implement the strategy of partnership between the public and private sectors in education should be carried out in the following areas:

- development of the national socially oriented PPP model in the field of education;

- formation of the legal basis of PPP in the field of vocational education;

- practical use of partnerships;

- definition of the prospects of the forms of partnership which takes into account the national policy, the developed methodological framework;

- systematization of measures of regulation, monitoring and stimulation of PPP in education through the creation of an institutional system in the field of educational services, the optimal model of information flows on PPP projects, and the system of controlling and monitoring the implementation of PPP.

In our opinion, the main conditions for ensuring the implementation of the system of training and advanced training in the conditions of public-private partnership involve the creation of:

- methodological, methodical and organizational base of the system;

- modern material and technical base, which provides for the wide use of technical training facilities;

- information base for the provision of filling of the information space; 
- systems of advanced training of teachers and their focus on advanced teaching methods;

- economic and motivational mechanism, and legal support of the system.

Consequently, specific practical work in the system of training and advanced training can be carried out by: universities; educational institutions of the system of advanced training, their branches and departments; state and commercial business education institutions; centers of in-house training - at basic organizations; centers for continuing education in enterprises and associations.

It is necessary to solve the problems of the regulation of the system of training and advanced training for small and medium-sized businesses. These include:

1) development of a comprehensive rational and municipal program for the development of human resources in the region, based on the system of orders for training personnel for entrepreneurship;

2) definition of the mechanism of allocation of grants for staff training;

3) licensing of some types of training activities to small and mediumsized enterprises, subject to the passage of appropriate training staff;

4) holding regional and municipal fairs of educational services;

5) rating of business education institutions in the region;

6) regulation of the quality of educational services within the framework of regional accreditation/licensing of educational institutions engaged in educational activities;

7) use of mass media to familiarize potential students with the regional educational system;

8) creation of a coordination center of the regional system of training and advanced training for small and medium-sized businesses.

Nevertheless, the role of the coordinator of the system at the first stage could be taken over by the division of the Administration of the region, city, and the district engaged in personnel policy of the region.

\section{Conclusion}

The benefits of the strategic partnership participants and the minimization of the costs of the integration process, taking into account the issues of risk delegation and responsibility between the participants of the public-private partnership, determine the degree of its effectiveness. Forms and methods of partnership depend on the maturity and national characteristics of market relations. At the same time, the state is not exempted from performing its social responsibility. Business, in turn, can be a source of development and the increment of new knowledge. The use of public-private partnership is the most effective in the implementation of long-term socially significant projects 
with a large amount of investment. Various forms of partnership allows us to share the risk of projects implementation between private and public sectors. This helps us to obtain long-term socio-economic effects. Thus, public-private partnership can lead to changes in economic relations between institutions of power and business due to the synergetic effect, reducing the degree of various types of contradictions, and creating conditions for solving problems that meet the public interest.

\section{References:}

1. Bondarenko, E.Y. (2008). Regional strategy of public-private partnership: world experience and Russian practice. Moscow, 204 p.

2. Deryabina, M. (2008). Public-private partnership: theory and practice.//Economic issue. №8.61-78 p.

3. Kolesnikova, L.A. (2010). Entrepreneurship and small business in the modern state: development management Moscow, $269 \mathrm{p}$.

4. Pierson, F. (1959). The education of American business: a study of university college programs in business administration / Pierson F. New York, McGraw-Hill.

5. Savransky, P.V. (2007). Public-private partnership in the implementation of promising directions of innovative development of the Russian economy. Krasnodar, $186 \mathrm{p}$.

6. Social and Economic Development of Kazakhstan (2017). Statistical yearbook. Astana, $112 \mathrm{p}$.

7. The Law of the Republic of Kazakhstan (2015). "On public-private partnership" dated 31 October. Astana. 